\title{
Peripheral Neuropathy as a Component of Skeletal Disease in Diabetes
}

\author{
Alec T. Beeve ${ }^{1,2}$ • Jennifer M. Brazill ${ }^{1}$ • Erica L. Scheller ${ }^{1,2,3}$ \\ Published online: 7 August 2019 \\ (C) The Author(s) 2019
}

\begin{abstract}
Purpose of Review The goal of this review is to explore clinical associations between peripheral neuropathy and diabetic bone disease and to discuss how nerve dysfunction may contribute to dysregulation of bone metabolism, reduced bone quality, and fracture risk.

Recent Findings Diabetic neuropathy can decrease peripheral sensation (sensory neuropathy), impair motor coordination (motor neuropathy), and increase postural hypotension (autonomic neuropathy). Together, this can impair overall balance and increase the risk for falls and fractures. In addition, the peripheral nervous system has the potential to regulate bone metabolism directly through the action of local neurotransmitters on bone cells and indirectly through neuroregulation of the skeletal vascular supply. Summary This review critically evaluates existing evidence for diabetic peripheral neuropathy as a risk factor or direct actor on bone disease. In addition, we address therapeutic and experimental considerations to guide patient care and future research evaluating the emerging relationship between diabetic neuropathy and bone health.
\end{abstract}

Keywords Diabetes $\cdot$ Neuropathy $\cdot$ Metabolic bone disease $\cdot$ Fracture $\cdot$ Microvascular disease $\cdot$ Marrow adiposity $\cdot$ Marrow fat

\section{Introduction}

In the nineteenth century, a fundamental link was established between neuropathy and skeletal disease. In 1868, JeanMartin Charcot, now considered a pioneer in the emerging field of neuroskeletal biology, reasoned that the pathogenesis of degenerative bone and joint disease was secondary to syphilitic damage to the spinal cord [1]. The proposed etiology for the disease, now referred to as Charcot neuroarthropathy, attracted debate and a series of investigations that together suggest a trifold pathological process mediating the complex

This article is part of the Topical Collection on Bone and Diabetes

Erica L. Scheller

scheller@wustl.edu

1 Department of Medicine, Division of Bone and Mineral Diseases, Washington University, 660 South Euclid Avenue, Saint Louis, MO 63110, USA

2 Department of Biomedical Engineering, Washington University, 6201 Forsyth Blvd, Saint Louis, MO 63105, USA

3 Department of Cell Biology and Physiology, Washington University, 660 South Euclid Avenue, Saint Louis, MO 63110, USA relationships between nerves and bone, including altered loading and microdamage (neurotraumatic), impaired local neurotransmitter release (neurotrophic), and reduced neural regulation of bone blood flow (neurovascular) [1]. With the rise of antibiotics and resulting decline of syphilis, diabetes has now emerged as the leading cause of neuroarthropathy [2]. Additionally, patients with type 1 and type 2 diabetes (T1D and T2D) develop significant changes in bone even in the absence of Charcot joint disease, which likewise increase fracture risk and decrease quality of life [3]. Recent investigations suggest that the same neuropathic processes responsible for neuroarthropathy may also contribute to the development of diabetic bone disease. Subsequent findings could not only aid in the prevention of debilitating neuroarthropathy and fracture but also provide an avenue to further study the relationships between nerve and bone health.

\section{Diabetic Bone Disease}

Though both diseases lead to increased fracture risk, the severity and nature of bone disease differs between patients with T1D and T2D. T1D is an early onset, autoimmune disorder that results in 
the destruction of pancreatic beta cells and systemic insulin deficiency [3]. Patients with T1D have decreased bone turnover [4] and a decrease in bone mineral density (BMD) which does not fully explain the $\sim 6$-fold increase in fracture risk $[5,6]$. When present, changes in skeletal microarchitecture in adults with T1D include decreased trabecular bone volume fraction, decreased cortical thickness, and increased bone size as measured by cross-sectional area and periosteal circumference $[7,8,9 \cdot \bullet, 10 \bullet$, 11]. In one study, the persistence of cortical and cross-sectional changes in adulthood was dependent on childhood onset of T1D [9••]. Indeed, several studies suggest that children and adolescents with T1D are at risk for decreased bone mass during development, which may prevent acquisition of optimal peak bone quantity, quality, and strength $[12,13 \bullet \bullet]$. Epidemiologic studies further indicate that early changes in T1D bone contribute to significant increases in fracture risk throughout the lifespan [14].

On the other hand, T2D is associated with a variety of genetic and environmental factors leading to insulin resistance, in which the biological efficacy of insulin is impaired [15]. As with T1D, T2D patients have decreased bone turnover and increased fracture risk, though both to a lesser extent [4-6]. Thirteen high-resolution peripheral quantitative computed tomography (HR-pQCT) studies of adult T2D bone have demonstrated that, despite significant heterogeneity, T2D is generally associated with limited to modest deficits in cortical bone density and area and, unlike T1D, relative preservation of or improvements in trabecular architecture $[8,16 \bullet, 17-19,20 \bullet \cdot, 21-23,24 \bullet, 25-27]$. In a recent study, trabecular improvements were limited to the early stages of T2D ( $<10$ years) [26], which may be related to increased loading due to larger body size or early hyperinsulinemia, prior to the onset of diabetic complications and co-morbidities. Though variable, an increase in cortical porosity is one of the more consistent findings by HR-pQCT in patients with T2D [16•, 17, 21], with a trend toward increased pore size even when compared directly to patients with T1D [8]. Increased cortical porosity is more prevalent in patients with a previous history of fracture [25, 27], with poor glucose control [18], or in the presence of microvascular disease [20••].

The pathogenesis of bone disease in diabetes likely represents several underlying processes which converge on bone in a disease-, stage-, age-, and even patient-specific manner (reviewed in $[3,28,29])$. This is a substantial clinical problem. Within the general population, $\sim 8-20 \%$ of older adult patients die within 1 year of hip fracture and $>50 \%$ never regain functional independence [30-33]. These outcomes are even worse for patients with diabetes, with higher rates of post-operative complications, longer hospital stays, substantial increases in mortality, greater frequency of pain/depression, and higher likelihood of nursing home placement [33-38]. Identification of novel, individualized risk factors, and mechanisms underlying diabetic bone disease and fracture risk is necessary to enhance treatments, thus prolonging health span in aging patients with diabetes.

\section{Diabetic Neuropathy}

Diabetic peripheral neuropathy (DPN) is a common complication of both T1D and T2D [39, 40] and a potential contributor to bone disease. About half of all diabetic patients are expected to develop DPN over the course of the disease, although studies disagree on whether prevalence is higher in T1D [41, 42], T2D [43••, 44], or similar in both [45]. DPN most often originates bilaterally in the long axons of the lower limbs and progresses proximally from the feet, affecting sensory, motor, and autonomic nerve fibers [46-48]. Degeneration of small sensory nerves is often, but not always, associated with painful, spiking sensations; this is followed by degeneration of large myelinated sensory fibers and associated numbness [49]. In addition to sensory dysfunction, patients with DPN may also present with other symptoms indicative of motor or autonomic dysfunction. For example, diabetic motor neuropathy may contribute to muscular atrophy [50] and autonomic neuropathy may precipitate cardiovascular, gastrointestinal, sudomotor, or urogenital dysfunction [48].

Like diabetic bone disease, DPN is a multifactorial complication with an evolving list of risk factors (reviewed in [46, 47]). While gaps remain in our understanding of its pathogenesis, hyperglycemia and dyslipidemia are indispensable to DPN onset and progression. These two factors, in concert with many others, are currently hypothesized to result in an acute metabolic stage (reversible) and a chronic structural stage (irreversible) of diabetic neuropathy [51]. In the acute metabolic stage, excess intracellular glucose is metabolized by one of three pathways: glycolysis, the hexosamine pathway, or the polyol pathway. Activation of these pathways results in the initiation of inflammatory cascades and the formation of reactive oxygen species, which can induce oxidative stress and disrupt nerve energy supply. Polyol pathway activation results in reduced $\mathrm{Na}^{+} / \mathrm{K}^{+}$-ATPase activity and accumulation of $\mathrm{Na}^{+}$ in the axon, impairing nerve excitability and slowing nerve conduction velocities [52-54].

In the chronic stage of DPN, degeneration of small and large nerve axons can be observed in the peripheral nervous system via teased fiber analysis, sural nerve biopsies, and skin punch biopsies [51, 55-57]. Axonal swelling from $\mathrm{Na}^{+}$accumulation disrupts connective junctions between Schwann cells and their associated axons [58]. Chronic hyperglycemia leads to formation of advanced glycation end products in neurons and Schwann cells, which can impair protein and cellular function, evoke inflammatory cascades, and result in additional oxidative stress [59,60]. Free fatty acids can damage Schwann cells directly and promote insulin resistance, and oxidation of lipoproteins and cholesterol can further increase oxidative stress and induce neuronal apoptosis [61-63]. In addition to direct nerve damage, the mechanisms described above also contribute to development of microvascular disease (MVD) that may lead to neural ischemia [64]. As 
structural damage proceeds, injured nerves may attempt to repair themselves, overexpressing persistent sodium channels, and releasing neuropeptides that may cause ectopic firing perceived as pain $[54,65]$, but ultimately, regeneration fails due to intrinsic neuronal deficits, Schwann cell dysfunction, and an unfavorable extracellular environment [46, 47]. Insurmountable chronic nerve injury leads to DPN, initially posing a threat to the limb, but also increasing the risk of death as it progresses proximally, affecting cardiovascular autonomic nerve fibers [46]. In addition to the heart, the impact of DPN on all innervated organs, including bone, needs to be considered in order to provide the most comprehensive care to patients with diabetes.

\section{Clinical Relationships Between Diabetic Bone Disease and Neuropathy}

To evaluate clinical associations between diabetic bone disease and DPN, a database search was performed on PubMed and Google using the following search keywords: "diabetes," "neuropathy," "microvascular disease," "microangiopathy," "bone mineral density," "bone microarchitecture," "bone serum markers," "fracture," and "bone healing complications." All studies with human patients were evaluated. Additional articles were obtained from reference lists. Individual articles from meta-analyses and systematic reviews were included, but not the meta-analyses themselves. Records only addressing retinopathy or nephropathy or relating to falls were excluded from our qualitative synthesis, as they are not the focus of this review. A summary of the articles and their findings is presented in Table 1.

Within the clinical literature, the presence of neuropathy, retinopathy, and nephropathy are often considered together as a proxy for MVD in diabetes $[4,7,18,20 \bullet, 71]$. Though this oversimplifies the pathogenesis of these disorders, the MVD model provides an excellent starting point to understand the relationship between diabetic complications and skeletal disease. To date, 15 clinical studies implicate a role for neuropathy alone, or neuropathy within the context of MVD, in higher fracture risk or reduced bone quality in T1D and T2D $[4,7,20 \bullet, 66-71,80,81,83 \bullet \bullet, 84-86]$ (Table 1). The most common explanation for the impact of MVD on fracture risk is loss of proprioception (neuropathy) and vision (retinopathy), increasing the likelihood of falls [90]. In addition, reduced physical ability and functional limitations develop alongside motor neuropathy and may contribute to reduced bone quality and increased fall risk in T1D and T2D [24•, $91,92]$. However, while a correlation with increased fall frequency has been confirmed [90, 93, 94], this view of diabetic complications, particularly DPN, likely underestimates the scope of its effects on bone health. DPN has been associated with reduced BMD or higher fracture risk in patients with
T1D in seven separate clinical studies [66-70, 84, 85]. Isolated cohorts of T2D are much less frequent $[18,20 \bullet, 74$, $80,83 \bullet \cdot, 86$ ] (Table 1), but one retrospective cohort of $2,798,309$ older male veterans found that as much as $21 \%$ of the increase in fracture risk in T2D was explained by neuropathy, making it the highest contributing factor of all complications examined $[83 \cdot \bullet$. In total, ten clinical studies have found strong associations between DPN, increased fracture risk, and/or reduced BMD [66-70, 81, 83••, 84-86]. Yet, an almost equal number find evidence to the contrary [72-79, 82, 87]. In some cases, multivariate models correcting for glycemic control and disease duration-factors often used to explain associations between neuropathy and fracture riskreduce the impact of DPN below significance [76, 87]. Hence, it remains unresolved whether neuropathy simply coevolves with diabetic bone disease due to similar pathological mechanisms (i.e., both serve as markers for disease duration or glycemic control), or if a causal relationship exists.

In addition to BMD and fracture, other measures of bone quality (e.g., microarchitecture, trabecular bone score) may relate to neuropathy in both T1D and T2D [28]. Two comprehensive studies by Shanbhogue et al evaluated the impact of MVD on bone density and microarchitecture using HR-pQCT in patients with T1D [7] and T2D [20••]. These studies are notable since they include comparisons between diabetic and non-diabetic MVD- patients and to non-diabetic MVD+ controls. Relative to age-matched, non-diabetic patients with MVD, T1D patients with MVD have significantly lower trabecular and cortical volumetric BMD, reduced cortical thickness, and increased periosteal circumference; when compared to diabetic patients without MVD, T1D is associated with additional decreases in trabecular volumetric BMD and thickness in the presence of microvascular complications [7]. T2D patients with MVD have more subtle changes in microarchitecture including trends toward increased cortical porosity, decreased cortical thickness, decreased cortical volumetric BMD, and, conversely to patients with T1D, increased trabecular bone mass $[20 \bullet \cdot$. These changes are not present in the diabetic MVD- groups when compared to agematched, non-diabetic MVD- controls. These studies suggest that adult patients with longstanding T1D (4 to 54 years) or T2D (10 to 17 years) have relatively preserved bone microarchitecture and, in the case of T1D, normal predicted bone strength in the absence of MVD [7, 18, 20••]. The underlying mechanisms associating MVD complications and diabetic bone disease remain unknown and controversial, particularly in regard to neuropathy. Current research is focused on defining whether these associations have positive predictive value for fracture, or beyond this, a direct impact on impaired bone health.

Bone healing represents another approach to characterize the effect of DPN on skeletal health. In one retrospective study, bone healing complications after foot or ankle surgery 


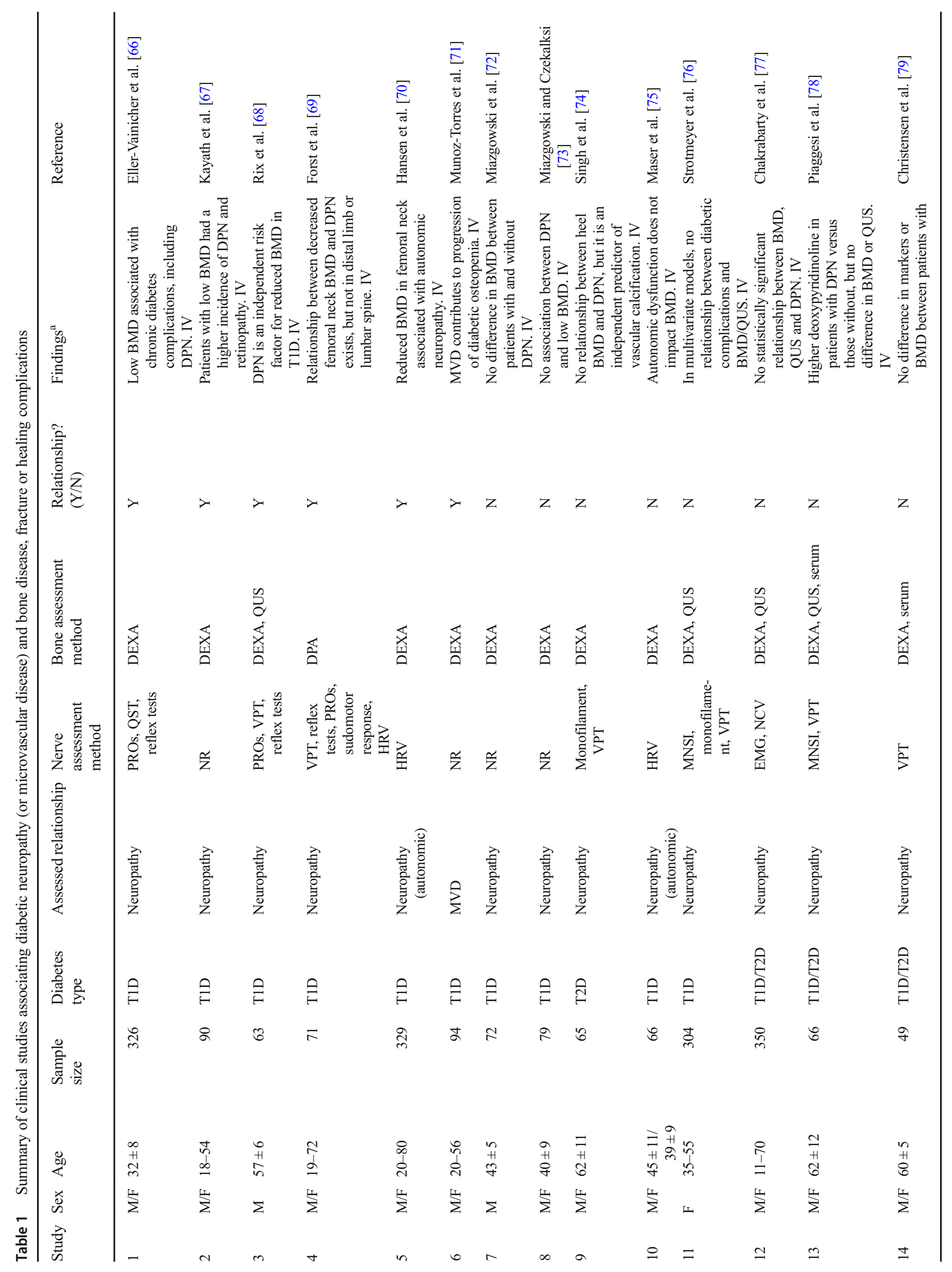




\begin{tabular}{|c|c|c|c|c|c|c|c|}
\hline 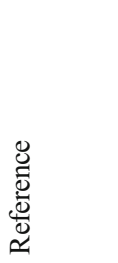 & 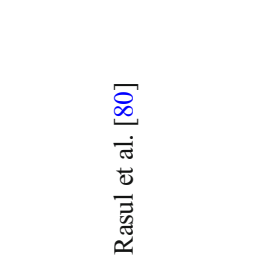 & 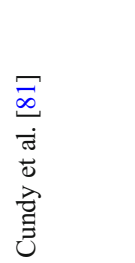 & 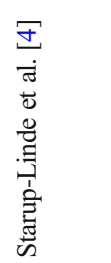 & 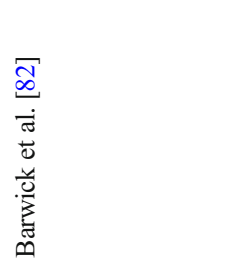 & 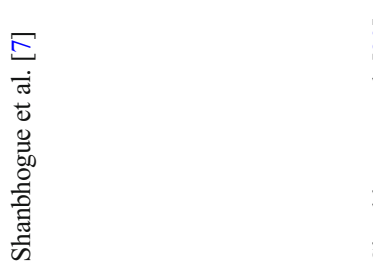 & 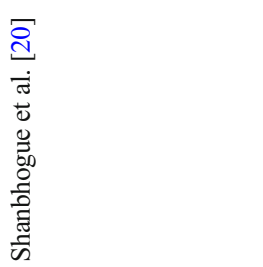 & 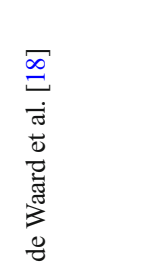 \\
\hline 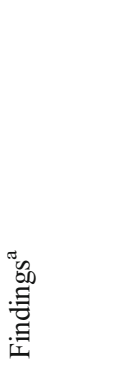 & 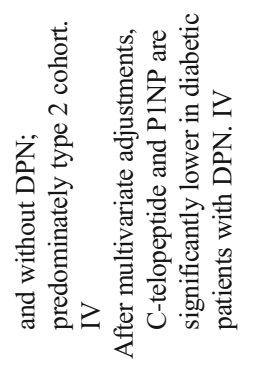 & 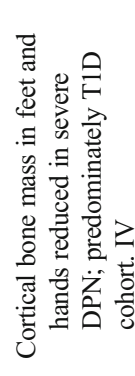 & 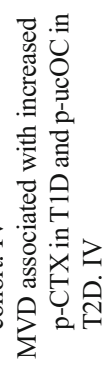 & 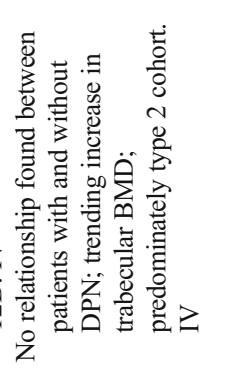 & 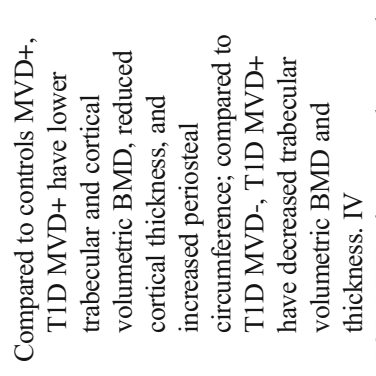 & 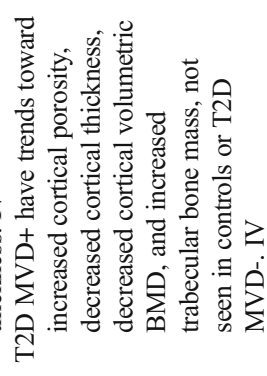 & 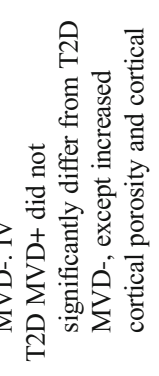 \\
\hline 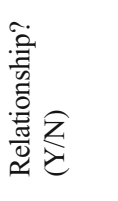 & 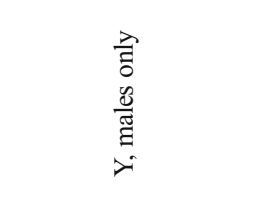 & $\lambda$ & $\succ$ & z & $\succ$ & $>$ & 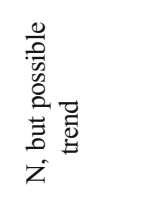 \\
\hline 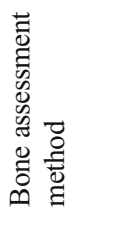 & 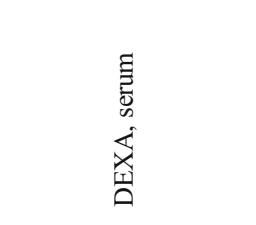 & & $\begin{array}{l}\text { 离 } \\
\text { 号 }\end{array}$ & $\underset{\check{Z}}{\underset{\partial}{2}}$ & 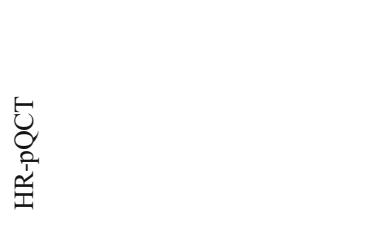 & 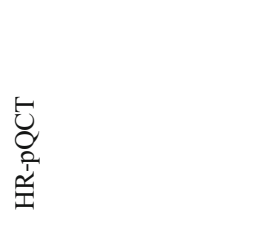 & 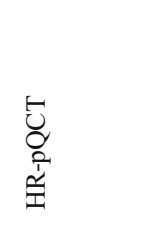 \\
\hline 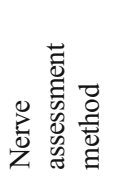 & 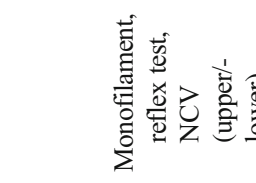 & 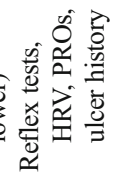 & 兑 & 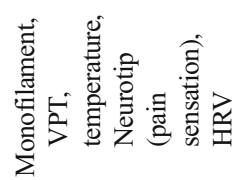 & 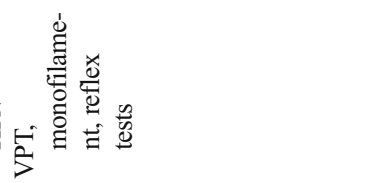 & 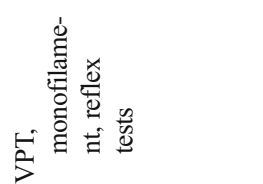 & $\stackrel{E}{\xi}$ \\
\hline 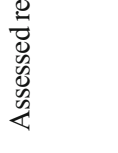 & 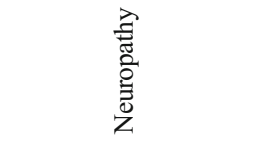 & 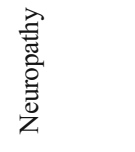 & $\sum_{\Sigma}$ & 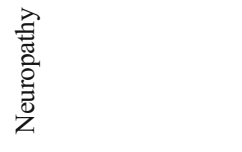 & $\sum$ & $\sum_{\Sigma}$ & $\sum$ \\
\hline 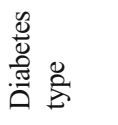 & & 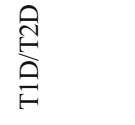 & $\begin{array}{l}\stackrel{\hat{~}}{\hat{~}} \\
\stackrel{F}{F}\end{array}$ & $\stackrel{\text { }}{\stackrel{\hat{E}}{\Theta}}$ & $\stackrel{\ominus}{\ominus}$ & & $\stackrel{\widehat{\mathrm{V}}}{ }$ \\
\hline 黄 & 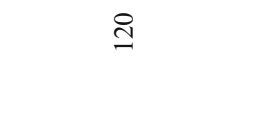 & $\vec{\gamma}$ & ¿ & f & $\stackrel{\ominus}{\Xi}$ & $\stackrel{\sigma}{\sigma}$ & $\stackrel{\circ}{\ni}$ \\
\hline 总 & $\begin{array}{l}\infty \\
\vdots \\
+\end{array}$ & $\begin{array}{l}\overrightarrow{0} \\
2\end{array}$ & $\begin{array}{l}5 \\
0 \\
\text { in }\end{array}$ & $\begin{array}{l}\infty \\
+1 \\
\gtrless\end{array}$ & $\begin{array}{l}\text { I } \\
\text { t } \\
+\end{array}$ & $\begin{array}{l}\stackrel{i}{1} \\
+\end{array}$ & $\frac{n}{\hat{j}}$ \\
\hline 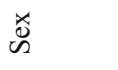 & $\sum_{\Sigma}^{L}$ & $\sum_{\Sigma}^{n}$ & $\sum_{\Sigma}^{L}$ & $\sum_{\Sigma}^{5}$ & $\sum_{\Sigma}^{1}$ & $\sum_{\Sigma}^{ \pm}$ & $\sum_{\Sigma}^{L}$ \\
\hline 总 & $\simeq$ & $\stackrel{0}{ }$ & $=$ & $\stackrel{\infty}{\sim}$ & $\Omega$ & iి & $\bar{N}$ \\
\hline
\end{tabular}




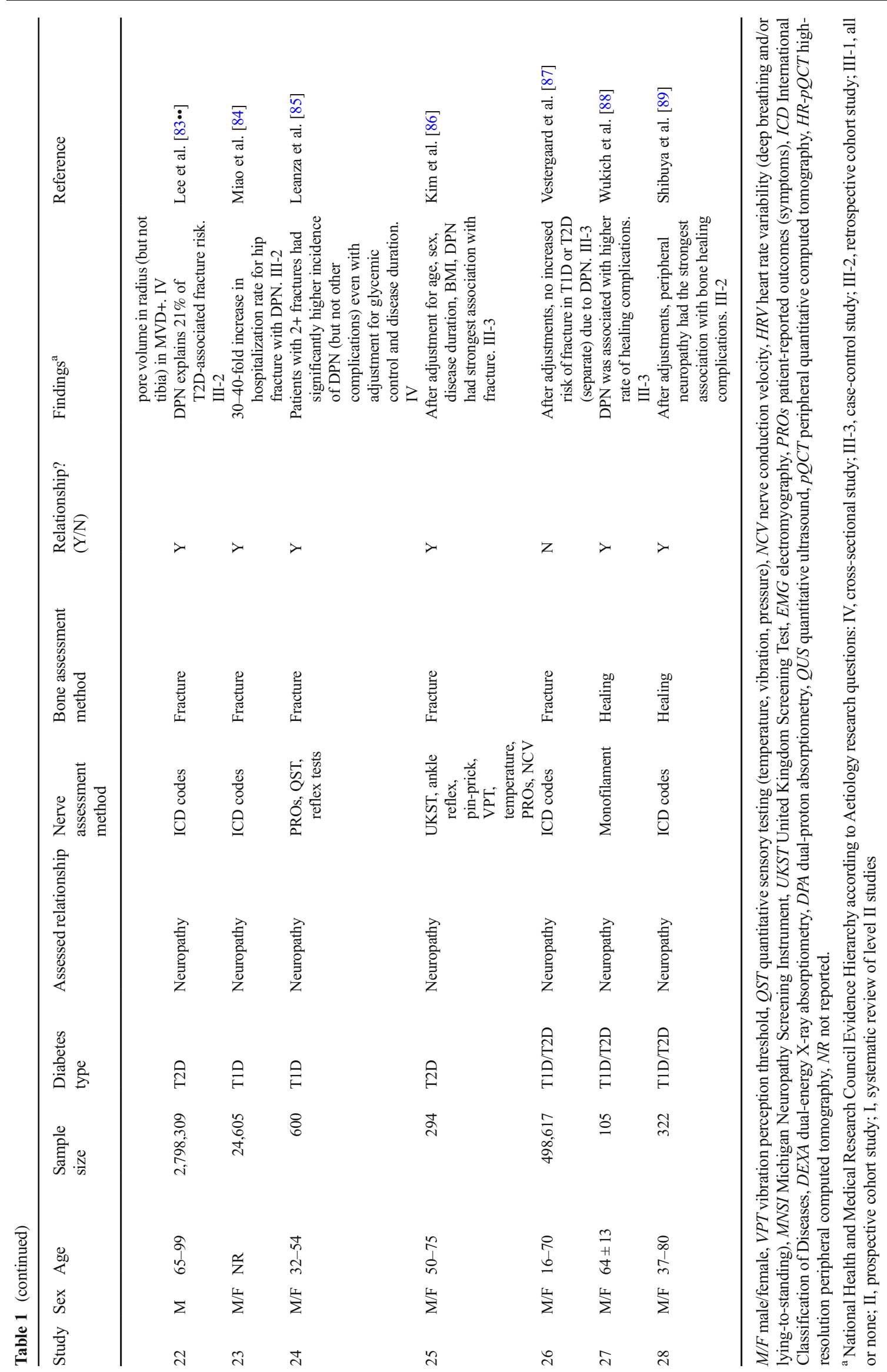


were observed with higher prevalence in diabetic patients with neuropathy (half of patients); in fact, DPN was considered the most important factor in determining bone healing complications such as nonunion, delayed union, or malunion [89]. A similar investigation observed that $76 \%$ of diabetic patients with DPN sustained post-operative healing complications after surgical treatment for ankle fracture [88]. However, neither study differentiated between T1D and T2D and the method of neuropathy diagnosis was limited to sensory neuropathy or unclearly stated.

Indeed, a key limitation within the current body of literature is a lack of consistency and comprehensiveness of neuropathy assessments and diagnoses. Comprehensive neuropathy assessments necessitate consideration of sensory, autonomic, and motor fibers. Some assessments, including nerve conduction velocity (NCV), monofilament tests, reflex tests, and vibration perception tests (VPT), are better suited for detecting large nerve fiber dysfunction (sensory and motor); others, including thermal tests, pinprick tests, and autonomic evaluations, are more indicative of small fiber involvement (autonomic and sensory) [48]. Assessments vary widely, especially in crosssectional studies; only three have clearly included separate assessments for large and small fiber neuropathy [66, $82,86]$. While sensory symptoms are the most common presentation of DPN, it is often concomitant with autonomic and motor neuropathy, both of which are relevant to bone. Only two clinical studies have attempted to isolate the impact of autonomic neuropathy on bone metabolism in T1D. The first concluded that no relationship exists; however, the study was limited by sample size and diagnostic tools, and there is growing evidence that autonomic neuropathy reduces BMD in T1D, at least in the trabecular compartment $[70,75]$. In addition, diabetic motor neuropathy may contribute to muscular atrophy in T1D [50], reducing muscle-mediated bone loading and myokine secretion that may be important to bone metabolism [95].

\section{Parsing the Potential Trifold Contributions of DPN to Diabetic Bone Disease}

An association between decreased bone health and neuropathy, independent of other MVD complications, is emerging. As eluded to in the introduction, relationships between nerve and bone health are generally segmented into three major categories: neurotraumatic, neurotrophic, and neurovascular (reviewed in [1]). The potential implications for each of these in the setting of diabetic bone disease will be discussed below.

1. Neurotraumatic contributions: impact of altered loading and microtrauma on bone
When it was first introduced by Volkman and Virchow to explain the pathogenesis of Charcot neuroarthropathy, the German neurotraumatic theory attributed neuropathic bone and joint degeneration to abnormal loading and unrecognized trauma or microfracture due to loss of proprioception and general sensation [96]. Changes in walking gait due to sensory and motor neuropathy and skeletal muscle atrophy have been noted in clinical studies of diabetic patients even without neuroarthropathy [97-99]. Resulting gait changes have the potential to subject bone to abnormal stresses, perhaps affecting bone quality even at mechanoresponsive sites far away from the joint [100]. Correlations between gait-related changes in skeletal loading, DPN, and focal changes in bone microarchitecture or mineral density have not yet been established, but represent an interesting area of future investigation.

2. Neurotrophic contributions: cellular and molecular mechanisms linking neuropathy and bone in diabetes

The bone and bone marrow are innervated by smalldiameter sensory and autonomic nerves, and a growing body of literature suggests that neurotrophic regulation of bone metabolism may play a role in skeletal homeostasis [1]. Bone maintenance, or remodeling, is carried out by basic multicellular units of osteoblasts and osteoclasts. Osteoclasts initially excavate a resorption space which is then filled with new bone by osteoblasts, creating osteons within the cortex and hemiosteons on the endocortical surface or within the cancellous bone compartment $[100,101]$. Dysregulation of this process can result in decreased cortical and trabecular bone, or increased cortical pore number and size, as has been observed in patients with T1D and T2D, respectively. Within the cortical bone, blood vessels and their associated nerves are recruited and extend through the newly formed osteon at a rate comparable to that achieved by the osteoclast cutting cone [101]. There is also evidence that nerve profiles are generally increased near active remodeling surfaces in human bone, particularly in the cortex $[102 \bullet \cdot$. The proximity of nerve fibers to bone cells suggests the possibility of direct regulatory actions on osteoblasts, osteoclasts, and osteocytes.

In a meta-analysis of clinical studies, circulating osteocalcin was the only biomarker that was consistently reduced in both T1D and T2D regardless of sex or age, reflecting common suppression of osteoblast recruitment and/or function across patient groups [103]. Regulation of osteoclasts may also occur, particularly in post-menopausal individuals; however, osteoclast biomarkers are highly heterogeneous between studies and patients [103]. In the presence of diabetic neuropathy, changes in local or systemic neurotransmitters due to altered production, impaired axonal transport, and/or loss of free nerve endings may contribute to these processes. For example, serum levels of calcitonin gene-related 
peptide (CGRP) and substance P, two sensory neuropeptides with osteoanabolic potential, were found to be reduced by $50 \%$ in adults with diabetes [104]. In addition, plasma catecholamine concentrations have been shown to be elevated in untreated diabetics [105] or reduced in patients with diabetic adrenergic neuropathy [106], suggesting potential for adrenergic neurotransmitter-mediated contributions to bone metabolism at different stages of disease.

It is also worth noting that osteocytes and bone marrow adipocytes represent alternative mediators of the coupling between nerve and bone in diabetes. Little is known about neurotrophic regulation of osteocytes; however, load-induced bone formation, commonly thought to be a key function of osteocytes, is hindered in animal models of diabetes [107-109], and a potential role of nerves in mediating load-induced bone formation is under investigation [110-112]. Bone marrow adipocytes are also increased in a subset of patients with diabetes (reviewed in [113]). Threedimensional electron microscopy imaging has revealed a close association of bone marrow adipocytes with sinusoidal vessels and sympathetic nerves, in close proximity to osteoblasts in mice, suggesting the potential for shared nerve-adipocyte-osteoblast regulatory pathways [114•].

3. Neurovascular contributions: changes in blood flow governing diabetic bone metabolism

Within human bone, $\sim 95 \%$ of nerves are associated with blood vessels [102••] and vasculogenesis is a key component of both bone modeling and remodeling [101]. Sympathetic adrenergic nerves mediate local vasoconstriction. By contrast, sensory neuropeptides CGRP and substance $\mathrm{P}$ are highly potent vasodilators [115]. CGRP and substance $\mathrm{P}$ can also promote angiogenesis $[116,117]$ and augment vascular permeability [118]. Thus, dysregulation of vascular perfusion of bone due to autonomic and sensory dysfunction in diabetic neuropathy represents another avenue through which DPN may contribute to diabetic bone disease. This is commonly referred to as the neurovascular theory. In addition, osteoclast and osteoblast progenitors are often derived from the circulation and the perivascular niche, respectively. Thus, diabetesassociated vascular disruptions may reduce access to these crucial progenitor depots.

Clinical studies which monitor peripheral limb blood flow via laser Doppler or scintigraphy have been performed in patients with diabetes; however, they generally have small sample sizes, contradictory results, and focus exclusively on Charcot neuroarthropathy. Three-phase bone scintigraphy of T2D patients with and without neuropathy was thought to reveal increased blood flow to bone even before the development of disease [119]. This could indicate a loss of sympathetic tone in the peripheral vasculature supplying the limb; however, a later study was unable to detect changes in venoarteriolar sympathetic axon reflex in association with neuroarthropathy [120], and another suggested that sympathetic neuropathy may actually protect against the development of neuroarthropathy [121]. Consensus has yet to be reached on a consistent relationship between vascular function and the development of diabetic bone disease. The challenge may lie in the changing nature of this relationship as the disease progresses and as additional complications arise. While sympathetic neuropathy in the peripheral vasculature may lead to dilation of blood vessels, vascular calcification and microangiopathy may also reduce effective sympathetic control of vascular tone. Longitudinal investigations and identification of proper assays are needed to evaluate this relationship both in neuroarthropathy and diabetic bone disease.

\section{Prospective Areas of Research and Future Directions}

Progressive characterization of the interplay between DPN and bone disease could play a pivotal role in advancing the field of neuroskeletal biology. Moving forward, clinical investigations will benefit from enhancing current study designs and expanding areas of research to promote more comprehensive and consistent neuropathy assessments, for example, inclusion of autonomic and motor modules in addition to sensory assays for both large and small fibers. These enhancements would not only improve neuropathy detection but may also provide adequate homogeneity for future meta-analysis. To date, the Michigan Neuropathy Screening Instrument (MNSI) has been one of the most widely applied chairside instruments for standardized clinical evaluation of diabetic peripheral sensory neuropathy [122]. Advanced techniques including electrophysiology and vascular studies are also possible but require expertise and equipment that is not widely available. To overcome this, an expansion of relatively noninvasive neuropathy diagnostic tools with supplemental or improved detection capabilities could reinvigorate clinical studies. For example, sudomotor tests (SudoScan) and corneal confocal microscopy are novel non-invasive detectors for peripheral autonomic and small fiber neuropathy, respectively [123, 124]. Most critically, prospective cohort studies in T1D and T2D with careful longitudinal assessments of both DPN and bone disease, starting close to onset, will be needed to establish the temporal relationship between these associated complications.

Paradigms for parsing the trifold contributions of DPN are largely undeveloped and represent a novel research frontier. Cross-sectional kinematic studies with bone assessments in diabetic patients with and without DPN may be an appropriate starting point for neurotraumatic contributions. Histological investigations of human diabetic bone may reveal the presence or absence of local neurotrophic relationships between skeletal nerves and bone cells in DPN. Ultimately though, 


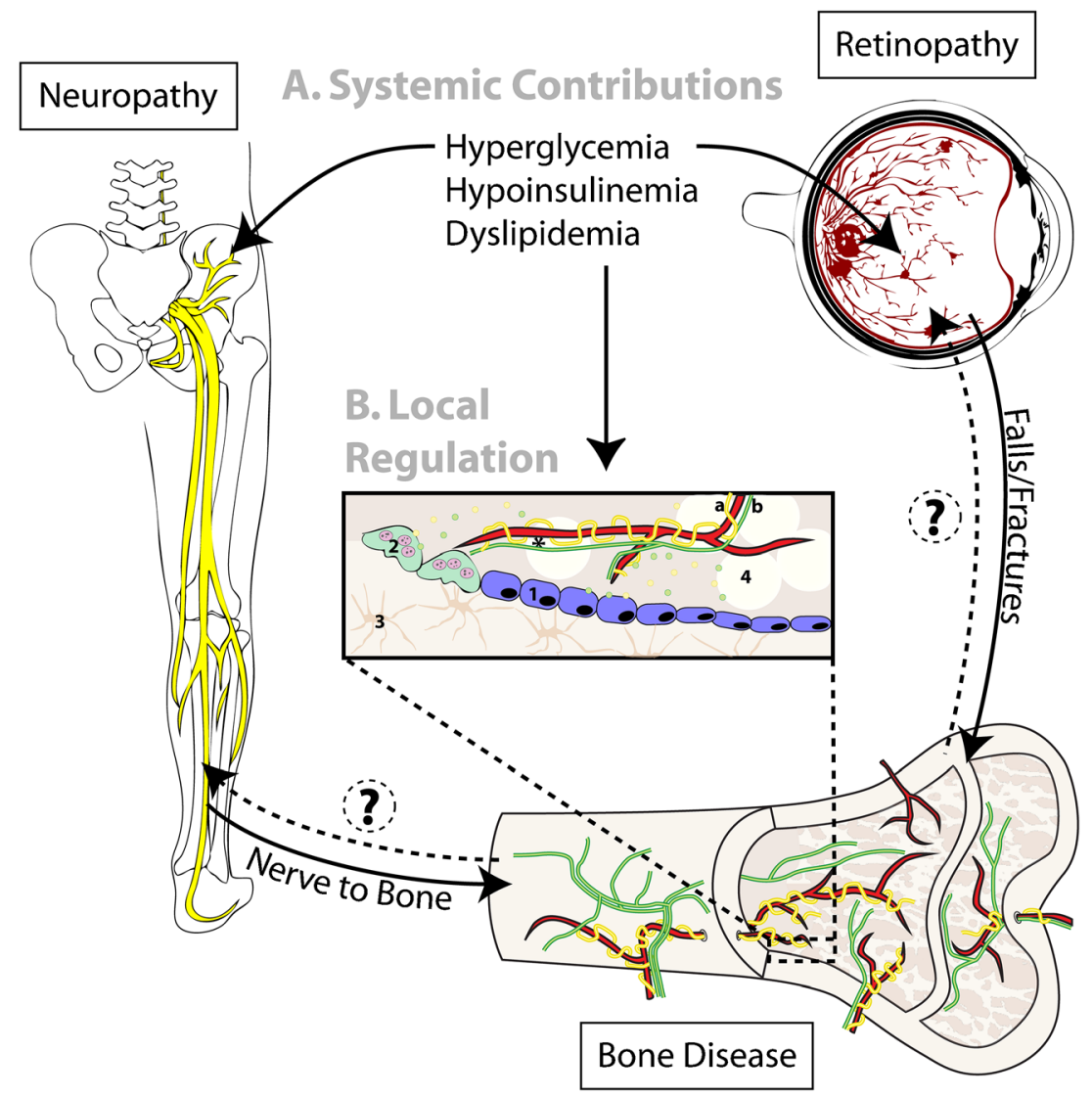

Fig. 1 Systemic and local relationships between diabetic neuropathy and bone health. a T1D and T2D result in hyperglycemia, hypoinsulinemia (T1D and some T2D), and dyslipidemia that impact multiple peripheral organ systems. These changes, among others, are part of a complex multifactorial set of systemic mediators that promote development of diabetic complications including peripheral neuropathy, retinopathy, and bone disease. Complications such as retinopathy can indirectly influence bone outcomes by increasing the risk of falls and fractures. Similarly, development of neuropathy can cause muscle weakness, altered gait, and impaired skeletal loading in addition to increasing risk of falls and fracture. b Beyond this, the skeleton is locally innervated by both (a, yellow) sympathetic adrenergic and (b, green) sensory peptidergic nerves. Secreted neurotransmitters have the capacity to act on surrounding cells including (1) osteoblasts, (2) osteoclasts, (3) osteocytes, and (4) bone marrow adipocytes. In addition, these neurotransmitters play a key role in regulating local vascular tone and permeability (*). Altogether, this provides many potential avenues for local regulation of bone metabolism and quality, which may be altered in the presence of neuropathy. (?) Emerging evidence also suggests that neural regulation of the bone marrow may stimulate release of circulating progenitors which promote tissue repair at distant sites. Thus, when present within bone, diabetic peripheral neuropathy may impair progenitor release, promoting further deterioration of both nerves (neuropathy) and vessels (retinopathy). Moving forward, both clinical and basic research is needed to establish which of these relationships are necessary and/or sufficient for destabilization of bone in patients with diabetes. This will promote optimization of therapeutics and interventions, promoting skeletal health across the lifespan developing this framework will require innovative collaborations between neurobiologists, bone biologists, and engineers to identify novel methods to specifically assess neurovascular function in bone and local cellular interaction between nerves and bone cells.

\section{Therapeutic Considerations for DPN and Diabetic Bone Disease}

DPN has great potential to influence bone metabolism and fracture risk though a diverse array of systemic and local mechanisms (Fig. 1). Conversely, there is emerging evidence in rodents and humans that neural regulation of the skeleton may be critical for maintenance of peripheral tissues in diabetes $[125,126]$. Specifically, damage to nerves within the bone marrow may restrict autonomicmediated release of circulating progenitor cells [125, 126], potentially contributing to further progression of diabetic complications including retinopathy and neuropathy $[126,127]$. This vicious cycle of disease provides an important context in which to consider interventions for patients with diabetes. It suggests that common strategies and therapeutics which simultaneously maintain or reestablish both nerve and bone health, and their relationship with one another, are needed and may subsequently have a positive impact on progression of other diabetic complications such as retinopathy. This, in turn, may limit 
falls and help to further decrease fracture. This integrated approach has great potential to reduce overall fracture risk and promote health span of aging diabetic individuals. These considerations may be especially important in adolescent-onset diabetes with longer disease duration. As much as $7 \%$ of adolescents with T1D and $22 \%$ of adolescents with T2D already have symptoms of neuropathy $[43 \cdot \bullet]$. Thus, early intervention may be critical to delay the onset of both nerve damage and skeletal disease in diabetes.

\section{Conclusions}

Peripheral neuropathy can have devastating consequences on quality and quantity of life. Due to its prevalence in both diabetic and non-diabetic populations, the relationships between nerves and their end-target organs merit comprehensive investigation. At this time, a compelling association is emerging between diabetic neuropathy and bone disease, but evidence is still forthcoming regarding the direct effects of diabetic neuropathy on bone or the utility of DPN as a predictor of skeletal fragility and fracture. To the authors' knowledge, no prospective cohorts with follow-up bone and nerve assessments exist within the current body of literature. In addition, variance in bone and nerve assessments and inclusion of mixed diabetic (T1D and T2D) cohorts may contribute to study heterogeneity (Table 1). While most associations between neuropathy and bone disease have been reduced to increased fall frequency, a trifold model of the nerve-bone axis may serve as a guide to study neuropathic contributions to skeletal fragility in diabetes. In addition to greater methodological cohesion, novel experimental approaches are needed to systematically interrogate this multifaceted relationship and to clarify the role of peripheral neuropathy as a component of skeletal disease in diabetes.

Funding information This work was supported by grants from the NIH including U01-DK116317, R00-DE024178, and T32-AR060719.

\section{Compliance with Ethical Standards}

Conflict of Interest Alec T Beeve, Jennifer M Brazill, and Erica L Scheller declare no conflict of interest.

Human and Animal Rights and Informed Consent This article does not contain any studies with human or animal subjects performed by any of the authors.

Open Access This article is distributed under the terms of the Creative Commons Attribution 4.0 International License (http:// creativecommons.org/licenses/by/4.0/), which permits unrestricted use, distribution, and reproduction in any medium, provided you give appropriate credit to the original author(s) and the source, provide a link to the Creative Commons license, and indicate if changes were made.

\section{References}

Papers of particular interest, published recently, have been highlighted as:

- Of importance

- Of major importance

1. Brazill JM, Beeve AT, Craft CS, Ivanusic JJ, Scheller EL. Nerves in bone: evolving concepts in pain and anabolism. J Bone Miner Res. 2019.

2. Rajbhandari SM, Jenkins RC, Davies C, Tesfaye S. Charcot neuroarthropathy in diabetes mellitus. Diabetologia. 2002;45: 1085-96.

3. Lecka-Czernik B, Fowlkes JL, editors. Diabetic bone disease. Cham: Springer International Publishing; 2016.

4. Starup-Linde J, Lykkeboe S, Gregersen S, Hauge E-M, Langdahl BL, Handberg A, et al. Differences in biochemical bone markers by diabetes type and the impact of glucose. Bone. 2016;83:149 55 .

5. Vestergaard P. Discrepancies in bone mineral density and fracture risk in patients with type 1 and type 2 diabetes-a meta-analysis. Osteoporos Int. 2007;18:427-44.

6. Janghorbani M, Van Dam RM, Willett WC, Hu FB. Systematic review of type 1 and type 2 diabetes mellitus and risk of fracture. Am J Epidemiol. 2007;166:495-505.

7. Shanbhogue VV, Hansen S, Frost M, Jørgensen NR, Hermann AP, Henriksen JE, et al. Bone geometry, volumetric density, microarchitecture, and estimated bone strength assessed by HRpQCT in adult patients with type 1 diabetes mellitus. J Bone Miner Res. 2015;30:2188-99.

8. Starup-Linde J, Lykkeboe S, Gregersen S, Hauge E-M, Langdahl $\mathrm{BL}$, Handberg A, et al. Bone structure and predictors of fracture in type 1 and type 2 diabetes. J Clin Endocrinol Metab. 2016;101: 928-36.

9.• Shah VN, Joshee P, Sippl R, Pyle L, Vigers T, Carpenter RD, et al. Type 1 diabetes onset at young age is associated with compromised bone quality. Bone. 2019;123:260-4 This article shows that compromised skeletal architecture in adults is linked to early development of T1D (age $<20$ ). With the recent realization that neuropathy is also prevalent in this younger age group, more work is needed to determine whether the nervebone axis is already impaired at an early age.

10. Verroken C, Pieters W, Beddeleem L, Goemaere S, Zmierczak HG, Shadid S, et al. Cortical bone size deficit in adult patients with type 1 diabetes mellitus. J Clin Endocrinol Metab. 2017;102: 2887-95 Demonstrates that adults with T1D have an endosteal deficit, leading to overall decreases in cortical bone. This implicates remodeling, in addition to modeling, in the pathogenesis of T1D-associated bone disease.

11. Abdalrahaman N, McComb C, Foster JE, McLean J, Lindsay RS, McClure J, et al. Deficits in trabecular bone microarchitecture in young women with type 1 diabetes mellitus. J Bone Miner Res. 2015;30:1386-93.

12. Moyer-Mileur LJ, Dixon SB, Quick JL, Askew EW, Murray MA. Bone mineral acquisition in adolescents with type 1 diabetes. $\mathrm{J}$ Pediatr. 2004;145:662-9.

13.• Maratova K, Soucek O, Matyskova J, Hlavka Z, Petruzelkova L, Obermannova B, et al. Muscle functions and bone strength are impaired in adolescents with type 1 diabetes. Bone. 2018;106: 22-7 This is the first study to comprehensively evaluate both muscle strength and bone quality in young patients with T1D. The results emphasize likely relationships between muscle health and bone health in diabetes. 
14. Weber DR, Haynes K, Leonard MB, Willi SM, Denburg MR. Type 1 diabetes is associated with an increased risk of fracture across the life span: a population-based cohort study using The Health Improvement Network (THIN). Diabetes Care. 2015;38: 1913-20.

15. Stumvoll M, Goldstein BJ, van Haeften TW. Type 2 diabetes: principles of pathogenesis and therapy. Lancet. 2005;365:133346.

16. Samelson EJ, Demissie S, Cupples LA, Zhang X, Xu H, Liu C-T, et al. Diabetes and deficits in cortical bone density, microarchitecture, and bone size: Framingham HR-pQCT study. J Bone Miner Res. 2018;33:54-62 The largest HR-pQCT-based analysis of bone microarchitecture in adult patients with T2D to date.

17. Yu EW, Putman MS, Derrico N, Abrishamanian-Garcia G, Finkelstein JS, Bouxsein ML. Defects in cortical microarchitecture among African-American women with type 2 diabetes. Osteoporos Int. 2015;26:673-9.

18. De Waard EAC, de Jong JJA, Koster A, Savelberg HHCM, van Geel TA, Houben AJHM, et al. The association between diabetes status, $\mathrm{HbAl}$ c, diabetes duration, microvascular disease, and bone quality of the distal radius and tibia as measured with highresolution peripheral quantitative computed tomography-the Maastricht study. Osteoporos Int. 2018;29:2725-38.

19. Patsch JM, Rasul S, Huber FA, Leitner K, Thomas A, Kocijan R, et al. Similarities in trabecular hypertrophy with site-specific differences in cortical morphology between men and women with type 2 diabetes mellitus. PLoS One. 2017;12:e0174664.

20.• Shanbhogue VV, Hansen S, Frost M, Jørgensen NR, Hermann AP, Henriksen JE, et al. Compromised cortical bone compartment in type 2 diabetes mellitus patients with microvascular disease. Eur J Endocrinol. 2016;174:115-24 This well-controlled study tests the relationship between microvascular complications, bone density and skeletal microarchitecture in patients with type 2 diabetes. This demonstrates that modest skeletal deficits are present in patients with both microvascular disease and diabetes, but not with diabetes alone.

21. Burghardt AJ, Issever AS, Schwartz AV, Davis KA, Masharani U, Majumdar S, et al. High-resolution peripheral quantitative computed tomographic imaging of cortical and trabecular bone microarchitecture in patients with type 2 diabetes mellitus. J Clin Endocrinol Metab. 2010;95:5045-55.

22. Shu A, Yin MT, Stein E, Cremers S, Dworakowski E, Ives R, et al. Bone structure and turnover in type 2 diabetes mellitus. Osteoporos Int. 2012;23:635-41.

23. Farr JN, Drake MT, Amin S, Melton LJ, McCready LK, Khosla S. In vivo assessment of bone quality in postmenopausal women with type 2 diabetes. J Bone Miner Res. 2014;29:787-95.

24. Nilsson AG, Sundh D, Johansson L, Nilsson M, Mellström D, Rudäng R, et al. Type 2 diabetes mellitus is associated with better bone microarchitecture but lower bone material strength and poorer physical function in elderly women: a population-based study. J Bone Miner Res. 2017;32:1062-71 This study combines HR-pQCT with in vivo biomaterial testing (Osteoprobe) in older women with T2D. This reveals that despite favorable microarchitecture, bone material properties were impaired and may explain increased fracture risk in this population.

25. Heilmeier U, Cheng K, Pasco C, Parrish R, Nirody J, Patsch JM, et al. Cortical bone laminar analysis reveals increased midcortical and periosteal porosity in type 2 diabetic postmenopausal women with history of fragility fractures compared to fracture-free diabetics. Osteoporos Int. 2016;27:2791-802.

26. Starr JF, Bandeira LC, Agarwal S, Shah AM, Nishiyama KK, Hu $\mathrm{Y}$, et al. Robust trabecular microstructure in type 2 diabetes revealed by individual Trabecula segmentation analysis of HRpQCT images. J Bone Miner Res. 2018;33:1665-75.
27. Patsch JM, Burghardt AJ, Yap SP, Baum T, Schwartz AV, Joseph GB, et al. Increased cortical porosity in type 2 diabetic postmenopausal women with fragility fractures. J Bone Miner Res. 2013;28:313-24.

28. Rubin MR. Skeletal fragility in diabetes. Ann N Y Acad Sci. 2017;1402:18-30.

29. Napoli N, Chandran M, Pierroz DD, Abrahamsen B, Schwartz AV, Ferrari SL, et al. Mechanisms of diabetes mellitus-induced bone fragility. Nat Rev Endocrinol. 2017;13:208-19.

30. Magaziner J, Simonsick EM, Kashner TM, Hebel JR, Kenzora JE. Survival experience of aged hip fracture patients. Am J Public Health. 1989;79:274-8.

31. Cooper C, Atkinson EJ, Jacobsen SJ, O'Fallon WM, Melton LJ. Population-based study of survival after osteoporotic fractures. Am J Epidemiol. 1993;137:1001-5.

32. Haentjens P, Magaziner J, Colón-Emeric CS, Vanderschueren D, Milisen K, Velkeniers B, et al. Meta-analysis: excess mortality after hip fracture among older women and men. Ann Intern Med. 2010;152:380-90.

33. Gulcelik NE, Bayraktar M, Caglar O, Alpaslan M, Karakaya J. Mortality after hip fracture in diabetic patients. Exp Clin Endocrinol Diabetes. 2011;119:414-8.

34. Wang H, Lü YW, Lan L, Zhang Q, Chen HL, Zhang GY, et al. Impact of diabetes on the prognosis of hip fracture: a cohort study in the Chinese population. Chin Med J. 2013;126:813-8.

35. Pan HH, Li CY, Chen PC, Lee MD, Liang CY, Hou WH, et al. Contributions of diabetic macro-vascular complications and hip fracture to depression onset in elderly patients with diabetes: an 8-year population-based follow-up study. J Psychosom Res. 2012;73:180-4.

36. Reistetter TA, Graham JE, Deutsch A, Markello SJ, Granger CV, Ottenbacher KJ. Diabetes comorbidity and age influence rehabilitation outcomes after hip fracture. Diabetes Care. 2011;34:13757.

37. Dubey A, Aharonoff GB, Zuckerman JD, Koval KJ. The effects of diabetes on outcome after hip fracture. Bull Hosp Jt Dis. 2000;59: 94-8.

38. Norris R, Parker M. Diabetes mellitus and hip fracture: a study of 5966 cases. Injury. 2011;42:1313-6.

39. Litwak L, Goh S-Y, Hussein Z, Malek R, Prusty V, Khamseh ME. Prevalence of diabetes complications in people with type 2 diabetes mellitus and its association with baseline characteristics in the multinational A1chieve study. Diabetol Metab Syndr. 2013;5:57.

40. Pambianco G, Costacou T, Ellis D, Becker DJ, Klein R, Orchard TJ. The 30-year natural history of type 1 diabetes complications: the Pittsburgh epidemiology of diabetes complications study experience. Diabetes. 2006;55:1463-9.

41. Løseth S, Mellgren SI, Jorde R, Lindal S, Stålberg E. Polyneuropathy in type 1 and type 2 diabetes: comparison of nerve conduction studies, thermal perception thresholds and intraepidermal nerve fibre densities. Diabetes Metab Res Rev. 2010;26:100-6.

42. Dyck PJ, Kratz KM, Karnes JL, Litchy WJ, Klein R, Pach JM, et al. The prevalence by staged severity of various types of diabetic neuropathy, retinopathy, and nephropathy in a population-based cohort: the Rochester diabetic neuropathy study. Neurology. 1993;43:817-24.

43.• Jaiswal M, Divers J, Dabelea D, Isom S, Bell RA, Martin CL, et al. Prevalence of and risk factors for diabetic peripheral neuropathy in youth with type 1 and type 2 diabetes: SEARCH for diabetes in youth study. Diabetes Care. 2017;40:1226-32 Unlike previous assumptions, this paper from the SEARCH cohort establishes diabetic neuropathy as a prevalent complication of both T1D and T2D youth.

44. Dabelea D, Stafford JM, Mayer-Davis EJ, D'Agostino R, Dolan L, Imperatore G, et al. Association of type 1 diabetes vs type 2 
diabetes diagnosed during childhood and adolescence with complications during teenage years and young adulthood. JAMA. 2017;317:825-35.

45. Eppens MC, Craig ME, Cusumano J, Hing S, Chan AKF, Howard NJ, et al. Prevalence of diabetes complications in adolescents with type 2 compared with type 1 diabetes. Diabetes Care. 2006;29: 1300-6.

46. Callaghan BC, Cheng HT, Stables CL, Smith AL, Feldman EL. Diabetic neuropathy: clinical manifestations and current treatments. Lancet Neurol. 2012;11:521-34.

47. Vincent AM, Callaghan BC, Smith AL, Feldman EL. Diabetic neuropathy: cellular mechanisms as therapeutic targets. Nat Rev Neurol. 2011;7:573-83.

48. Pop-Busui R, Boulton AJM, Feldman EL, Bril V, Freeman R, Malik RA, et al. Diabetic neuropathy: a position statement by the American diabetes association. Diabetes Care. 2017;40:136-54.

49. Britland ST, Young RJ, Sharma AK, Clarke BF. Association of painful and painless diabetic polyneuropathy with different patterns of nerve fiber degeneration and regeneration. Diabetes. 1990;39:898-908.

50. Sala D, Zorzano A. Differential control of muscle mass in type 1 and type 2 diabetes mellitus. Cell Mol Life Sci. 2015;72:3803-17.

51. Biessels GJ, Bril V, Calcutt NA, Cameron NE, Cotter MA, Dobrowsky R, et al. Phenotyping animal models of diabetic neuropathy: a consensus statement of the diabetic neuropathy study group of the EASD (Neurodiab). J Peripher Nerv Syst. 2014;19: $77-87$.

52. Arnold R, Kwai N, Lin CS-Y, Poynten AM, Kiernan MC, Krishnan AV. Axonal dysfunction prior to neuropathy onset in type 1 diabetes. Diabetes Metab Res Rev. 2013;29:53-9.

53. Sung J-Y, Tani J, Chang T-S, Lin CS-Y. Uncovering sensory axonal dysfunction in asymptomatic type 2 diabetic neuropathy. PLoS One. 2017;12:e171223.

54. Misawa S, Sakurai K, Shibuya K, Isose S, Kanai K, Ogino J, et al. Neuropathic pain is associated with increased nodal persistent $\mathrm{Na}(+)$ currents in human diabetic neuropathy. J Peripher Nerv Syst. 2009;14:279-84.

55. Malik RA, Tesfaye S, Newrick PG, Walker D, Rajbhandari SM, Siddique I, et al. Sural nerve pathology in diabetic patients with minimal but progressive neuropathy. Diabetologia. 2005;48:578-85.

56. Lindberger M, Schröder HD, Schultzberg M, Kristensson K, Persson A, Ostman J, et al. Nerve fibre studies in skin biopsies in peripheral neuropathies. I. Immunohistochemical analysis of neuropeptides in diabetes mellitus. J Neurol Sci. 1989;93:289-96.

57. Tesfaye S, Boulton AJM, Dyck PJ, Freeman R, Horowitz M, Kempler P, et al. Diabetic neuropathies: update on definitions, diagnostic criteria, estimation of severity, and treatments. Diabetes Care. 2010;33:2285-93.

58. Sima AA, Nathaniel V, Bril V, McEwen TA, Greene DA. Histopathological heterogeneity of neuropathy in insulindependent and non-insulin-dependent diabetes, and demonstration of axo-glial dysjunction in human diabetic neuropathy. $\mathrm{J}$ Clin Invest. 1988;81:349-64.

59. Vincent AM, Perrone L, Sullivan KA, Backus C, Sastry AM, Lastoskie C, et al. Receptor for advanced glycation end products activation injures primary sensory neurons via oxidative stress. Endocrinology. 2007;148:548-58.

60. Duran-Jimenez B, Dobler D, Moffatt S, Rabbani N, Streuli CH, Thornalley PJ, et al. Advanced glycation end products in extracellular matrix proteins contribute to the failure of sensory nerve regeneration in diabetes. Diabetes. 2009;58:2893-903.

61. Almaguel FG, Liu J-W, Pacheco FJ, De Leon D, Casiano CA, De Leon M. Lipotoxicity-mediated cell dysfunction and death involve lysosomal membrane permeabilization and cathepsin L activity. Brain Res. 2010;1318:133-43.
62. Tsintzas K, Chokkalingam K, Jewell K, Norton L, Macdonald IA, Constantin-Teodosiu D. Elevated free fatty acids attenuate the insulin-induced suppression of PDK4 gene expression in human skeletal muscle: potential role of intramuscular long-chain acylcoenzyme A. J Clin Endocrinol Metab. 2007;92:3967-72.

63. Vincent AM, Hayes JM, McLean LL, Vivekanandan-Giri A, Pennathur S, Feldman EL. Dyslipidemia-induced neuropathy in mice: the role of oxLDL/LOX-1. Diabetes. 2009;58:2376-85.

64. Tesfaye S, Harris N, Jakubowski JJ, Mody C, Wilson RM, Rennie IG, et al. Impaired blood flow and arterio-venous shunting in human diabetic neuropathy: a novel technique of nerve photography and fluorescein angiography. Diabetologia. 1993;36:126674.

65. Wu G, Ringkamp M, Murinson BB, Pogatzki EM, Hartke TV, Weerahandi HM, et al. Degeneration of myelinated efferent fibers induces spontaneous activity in uninjured $\mathrm{C}$-fiber afferents. J Neurosci. 2002;22:7746-53.

66. Eller-Vainicher C, Zhukouskaya VV, Tolkachev YV, Koritko SS, Cairoli E, Grossi E, et al. Low bone mineral density and its predictors in type 1 diabetic patients evaluated by the classic statistics and artificial neural network analysis. Diabetes Care. 2011;34: 2186-91.

67. Kayath MJ, Dib SA, Vieira JG. Prevalence and magnitude of osteopenia associated with insulin-dependent diabetes mellitus. J Diabetes Complicat. 1994;8:97-104.

68. Rix M, Andreassen H, Eskildsen P. Impact of peripheral neuropathy on bone density in patients with type 1 diabetes. Diabetes Care. 1999;22:827-31.

69. Forst T, Pfützner A, Kann P, Schehler B, Lobmann R, Schäfer H, et al. Peripheral osteopenia in adult patients with insulindependent diabetes mellitus. Diabet Med. 1995;12:874-9.

70. Hansen CS, Theilade S, Lajer M, Hansen TW, Rossing P. Cardiovascular autonomic neuropathy and bone metabolism in type 1 diabetes. Diabet Med. 2018;35:1596-604.

71. Muñoz-Torres M, Jódar E, Escobar-Jiménez F, López-Ibarra PJ, Luna JD. Bone mineral density measured by dual X-ray absorptiometry in Spanish patients with insulin-dependent diabetes mellitus. Calcif Tissue Int. 1996;58:316-9.

72. Miazgowski T, Pynka S, Noworyta-Zietara M, KrzyzanowskaSwiniarska B, Pikul R. Bone mineral density and hip structural analysis in type 1 diabetic men. Eur J Endocrinol. 2007;156:123-7.

73. Miazgowski T, Czekalski S. A 2-year follow-up study on bone mineral density and markers of bone turnover in patients with long-standing insulin-dependent diabetes mellitus. Osteoporos Int. 1998;8:399-403.

74. Singh DK, Winocour P, Summerhayes B, Kaniyur S, Viljoen A, Sivakumar G, et al. The foot in type 2 diabetes: is there a link between vascular calcification and bone mineral density? Diabetes Res Clin Pract. 2011;94:410-6.

75. Maser RE, Stabley JN, Lenhard MJ, Provost-Craig MA. Autonomic nerve fiber function and bone mineral density in individuals with type 1 diabetes: a cross-sectional study. Diabetes Res Clin Pract. 2009;84:252-8.

76. Strotmeyer ES, Cauley JA, Orchard TJ, Steenkiste AR, Dorman JS. Middle-aged premenopausal women with type 1 diabetes have lower bone mineral density and calcaneal quantitative ultrasound than nondiabetic women. Diabetes Care. 2006;29:306-11.

77. Chakrabarty N, Sarkar P, Pal SK, Banerjee R, Sarkar RN, Debnath NB. A study of bone mineral density in diabetes mellitus in eastern India. J Indian Med Assoc. 2004;102:418 420, 422 passim.

78. Piaggesi A, Rizzo L, Golia F, Costi D, Baccetti F, Ciaccio S, et al. Biochemical and ultrasound tests for early diagnosis of active neuro-osteoarthropathy (NOA) of the diabetic foot. Diabetes Res Clin Pract. 2002;58:1-9.

79. Christensen TM, Bülow J, Simonsen L, Holstein PE, Svendsen OL. Bone mineral density in diabetes mellitus patients with and 
without a Charcot foot. Clin Physiol Funct Imaging. 2010;30: $130-4$.

80. Rasul S, Ilhan A, Wagner L, Luger A, Kautzky-Willer A. Diabetic polyneuropathy relates to bone metabolism and markers of bone turnover in elderly patients with type 2 diabetes: greater effects in male patients. Gend Med. 2012;9:187-96.

81. Cundy TF, Edmonds ME, Watkins PJ. Osteopenia and metatarsal fractures in diabetic neuropathy. Diabet Med. 1985;2:461-4.

82. Barwick AL, Tessier JW, Janse de Jonge X, Chuter VH. Foot bone density in diabetes may be unaffected by the presence of neuropathy. J Diabetes Complicat. 2016;30:1087-92.

83.• Lee RH, Sloane R, Pieper C, Lyles KW, Adler RA, Van Houtven $\mathrm{C}$, et al. Clinical fractures among older men with diabetes are mediated by diabetic complications. J Clin Endocrinol Metab. 2018;103:281-7 This well-powered study of $\mathbf{2 , 7 9 8 , 3 0 9}$ veterans, including 900,402 with diabetes, found that older male veterans with diabetes have a significant increase in risk of incident clinical fracture. Within this cohort peripheral neuropathy was identified as a significant mediating factor for diabetes-associated fracture.

84. Miao J, Brismar K, Nyrén O, Ugarph-Morawski A, Ye W. Elevated hip fracture risk in type 1 diabetic patients: a population-based cohort study in Sweden. Diabetes Care. 2005;28:2850-5.

85. Leanza G, Maddaloni E, Pitocco D, Conte C, Palermo A, Maurizi $\mathrm{AR}$, et al. Risk factors for fragility fractures in type 1 diabetes. Bone. 2019;125:194-9.

86. Kim J-H, Jung M-H, Lee J-M, Son H-S, Cha B-Y, Chang S-A. Diabetic peripheral neuropathy is highly associated with nontraumatic fractures in Korean patients with type 2 diabetes mellitus. Clin Endocrinol (Oxf). 2012;77:51-5.

87. Vestergaard P, Rejnmark L, Mosekilde L. Diabetes and its complications and their relationship with risk of fractures in type 1 and 2 diabetes. Calcif Tissue Int. 2009;84:45-55.

88. Wukich DK, Joseph A, Ryan M, Ramirez C, Irrgang JJ. Outcomes of ankle fractures in patients with uncomplicated versus complicated diabetes. Foot Ankle Int. 2011;32:120-30.

89. Shibuya N, Humphers JM, Fluhman BL, Jupiter DC. Factors associated with nonunion, delayed union, and malunion in foot and ankle surgery in diabetic patients. J Foot Ankle Surg. 2013;52: 207-11.

90. Schwartz AV, Vittinghoff E, Sellmeyer DE, Feingold KR, de Rekeneire N, Strotmeyer ES, et al. Diabetes-related complications, glycemic control, and falls in older adults. Diabetes Care. 2008;31:391-6.

91. Resnick HE, Vinik AI, Schwartz AV, Leveille SG, Brancati FL, Balfour J, et al. Independent effects of peripheral nerve dysfunction on lower-extremity physical function in old age: the Women's Health and Aging study. Diabetes Care. 2000;23:1642-7.

92. Kanazawa I, Takeno A, Tanaka K-I, Yamane Y, Sugimoto T. Osteoporosis and vertebral fracture are associated with deterioration of activities of daily living and quality of life in patients with type 2 diabetes mellitus. J Bone Miner Metab. 2018.

93. Richardson JK, Hurvitz EA. Peripheral neuropathy: a true risk factor for falls. J Gerontol A Biol Sci Med Sci. 1995;50:M211-5.

94. Rasmussen NH, Dal J. Falls and fractures in diabetes-more than bone fragility. Curr Osteoporos Rep. 2019;17:147-56.

95. Avin KG, Bloomfield SA, Gross TS, Warden SJ. Biomechanical aspects of the muscle-bone interaction. Curr Osteoporos Rep. 2015;13:1-8.

96. Kaynak G, Birsel O, Güven MF, Ogüt T. An overview of the Charcot foot pathophysiology. Diabetic Foot Ankle. 2013;4.

97. Gomes AA, Ackermann M, Ferreira JP, Orselli MIV, Sacco ICN. Muscle force distribution of the lower limbs during walking in diabetic individuals with and without polyneuropathy. J Neuroeng Rehabil. 2017;14:111.
98. Parasoglou P, Rao S, Slade JM. Declining skeletal muscle function in diabetic peripheral neuropathy. Clin Ther. 2017;39:1085-103.

99. D'Silva LJ, Lin J, Staecker H, Whitney SL, Kluding PM. Impact of diabetic complications on balance and falls: contribution of the vestibular system. Phys Ther. 2016;96:400-9.

100. Van Oers RF, Ruimerman R, Tanck E, Hilbers PA, Huiskes R. A unified theory for osteonal and hemi-osteonal remodeling. Bone. 2008;42:250-9.

101. Parfitt AM. Osteonal and hemi-osteonal remodeling: the spatial and temporal framework for signal traffic in adult human bone. $\mathrm{J}$ Cell Biochem. 1994;55:273-86.

102.• Sayilekshmy M, Hansen RB, Delaissé J-M, Rolighed L, Andersen TL, Heegaard A-M. Innervation is higher above bone remodeling surfaces and in cortical pores in human bone: lessons from patients with primary hyperparathyroidism. Sci Rep. 2019;9:5361 This is one of the first quantitative studies of nerve density in human bone. This work clearly demonstrates that nerves in bone are predominantly, if not exclusively, associated with the vasculature. In addition, neurovascular bundles were preferentially identified above remodeling surfaces, suggesting that local neurotransmitters may contribute to bone remodeling.

103. Starup-Linde J, Eriksen SA, Lykkeboe S, Handberg A, Vestergaard P. Biochemical markers of bone turnover in diabetes patients-a meta-analysis, and a methodological study on the effects of glucose on bone markers. Osteoporos Int. 2014;25:1697-708.

104. Wang LH, Zhou SX, Li RC, Zheng LR, Zhu JH, Hu SJ, et al. Serum levels of calcitonin gene-related peptide and substance $\mathrm{P}$ are decreased in patients with diabetes mellitus and coronary artery disease. J Int Med Res. 2012;40:134 40.

105. Christensen NJ. Catecholamines and diabetes mellitus. Diabetologia. 1979;16:211-24.

106. Cryer PE, Silverberg AB, Santiago JV, Shah SD. Plasma catecholamines in diabetes. The syndromes of hypoadrenergic and hyperadrenergic postural hypotension. Am J Med. 1978;64:407-16.

107. Kalaitzoglou E, Popescu I, Bunn RC, Fowlkes JL, Thrailkill KM. Effects of type 1 diabetes on osteoblasts, osteocytes, and osteoclasts. Curr Osteoporos Rep. 2016;14:310-9.

108. Parajuli A, Liu C, Li W, Gu X, Lai X, Pei S, et al. Bone's responses to mechanical loading are impaired in type 1 diabetes. Bone. 2015;81:152-60.

109. Seref-Ferlengez Z, Suadicani SO, Thi MM. A new perspective on mechanisms governing skeletal complications in type 1 diabetes. Ann N Y Acad Sci. 2016;1383:67-79.

110. Sample SJ, Behan M, Smith L, Oldenhoff WE, Markel MD, Kalscheur VL, et al. Functional adaptation to loading of a single bone is neuronally regulated and involves multiple bones. $\mathrm{J}$ Bone Miner Res. 2008;23:1372-81.

111. Wu Q, Sample SJ, Baker TA, Thomas CF, Behan M, Muir P. Mechanical loading of a long bone induces plasticity in sensory input to the central nervous system. Neurosci Lett. 2009;463:254-7.

112. Lau YC, Qian X, Po KT, Li LM, Guo X. Electrical stimulation at the dorsal root ganglion preserves trabecular bone mass and microarchitecture of the tibia in hindlimb-unloaded rats. Osteoporos Int. 2015;26:481-8.

113. Schwartz AV. Marrow fat and bone: review of clinical findings. Front Endocrinol (Lausanne). 2015;6:40.

114. Robles H, Park S, Joens MS, Fitzpatrick JAJ, Craft CS, Scheller EL. Characterization of the bone marrow adipocyte niche with three-dimensional electron microscopy. Bone. 2019;118:89-98 This unique, three-dimensional study of the bone marrow niche reveals that terminal autonomic nerve endings may be located at the interface of bone marrow adipocytes and osteoblasts, suggesting a novel role for the local nerve-fat-bone axis in bone turnover. 
115. Kee Z, Kodji X, Brain SD. The role of calcitonin gene related peptide (CGRP) in neurogenic vasodilation and its cardioprotective effects. Front Physiol. 2018;9:1249.

116. Ziche M, Morbidelli L, Pacini M, Geppetti P, Alessandri G, Maggi CA. Substance $P$ stimulates neovascularization in vivo and proliferation of cultured endothelial cells. Microvasc Res. 1990;40:264-78.

117. Mapp PI, McWilliams DF, Turley MJ, Hargin E, Walsh DA. A role for the sensory neuropeptide calcitonin gene-related peptide in endothelial cell proliferation in vivo. Br J Pharmacol. 2012;166: 1261-71.

118. Brain SD, Williams TJ. Inflammatory oedema induced by synergism between calcitonin gene-related peptide (CGRP) and mediators of increased vascular permeability. Br J Pharmacol. 1985;86: 855-60.

119. Edmonds ME, Clarke MB, Newton S, Barrett J, Watkins PJ. Increased uptake of bone radiopharmaceutical in diabetic neuropathy. Q J Med. 1985;57:843-55.

120. Christensen TM, Simonsen L, Holstein PE, Svendsen OL, Bülow J. Sympathetic neuropathy in diabetes mellitus patients does not elicit Charcot osteoarthropathy. J Diabetes Complicat. 2011;25: $320-4$.

121. Shapiro SA, Stansberry KB, Hill MA, Meyer MD, McNitt PM, Bhatt BA, et al. Normal blood flow response and vasomotion in the diabetic charcot foot. J Diabetes Complicat. 1998;12:147-53.

122. Jaiswal M, Lauer A, Martin CL, Bell RA, Divers J, Dabelea D, et al. Peripheral neuropathy in adolescents and young adults with type 1 and type 2 diabetes from the SEARCH for diabetes in youth follow-up cohort: a pilot study. Diabetes Care. 2013;36:3903-8.
123. Khan A, Petropoulos IN, Ponirakis G, Menzies RA, Chidiac O, Pasquier J, et al. Corneal confocal microscopy detects severe small fiber neuropathy in diabetic patients with Charcot neuroarthropathy. J Diabetes Investig. 2018;9:1167-72.

124. Casellini CM, Parson HK, Richardson MS, Nevoret ML, Vinik AI. Sudoscan, a noninvasive tool for detecting diabetic small fiber neuropathy and autonomic dysfunction. Diabetes Technol Ther. 2013;15:948-53.

125. Albiero M, Poncina N, Tjwa M, Ciciliot S, Menegazzo L, Ceolotto G, et al. Diabetes causes bone marrow autonomic neuropathy and impairs stem cell mobilization via dysregulated p66Shc and Sirt1. Diabetes. 2014;63:1353-65.

126. Busik JV, Tikhonenko M, Bhatwadekar A, Opreanu M, Yakubova $\mathrm{N}$, Caballero $\mathrm{S}$, et al. Diabetic retinopathy is associated with bone marrow neuropathy and a depressed peripheral clock. J Exp Med. 2009;206:2897-906.

127. Jeong JO, Kim MO, Kim H, Lee MY, Kim SW, Ii M, et al. Dual angiogenic and neurotrophic effects of bone marrow-derived endothelial progenitor cells on diabetic neuropathy. Circulation. 2009;119:699-708.

Publisher's Note Springer Nature remains neutral with regard to jurisdictional claims in published maps and institutional affiliations. 